\title{
Análise das mediações do pop-popular do videoclipe Flei
}

\section{Analysis of the mediations of the pop music video Flei}

Jeder Janotti Junior

Universidade Federal de Pernambuco

<jederjr@gmail.com>

\author{
João André Alcantara \\ Universidade Federal de Pernambuco \\ <joaoandrealcantara@gmail.com>
}

\author{
Como citar este artigo (How to cite this article): \\ JANOTTI JUNIOR, Jeder; ALCANTARA, João André. Análise das mediações do pop-popular do videoclipe Flei. \\ Revista Famecos, Porto Alegre, v. 25, n. 2, p. 1-19, maio, junho, julho e agosto de 2018: ID27641. \\ DOI: http://dx.doi.org/10.15448/1980-3729.2018.2.27641.
}

\section{RESUMO}

Este artigo propõe uma análise do videoclipe Flei, levando em consideração as articulações entre gênero, gênero musical e plataformas on-line de disponibilização de conteúdos musicais. Acreditase que para compreender o que é um videoclipe devemos levar em consideração o papel que as novas mediações audiovisuais desempenham em um ambiente onde a grade televisiva já não tem a importância que tinha na era MTV. Assim, buscamos analisar o videoclipe da canção "Flei", do cantor Daniel Peixoto, apontando como as assinaturas de gênero e gênero musical são articuladas de modo político e estético. A partir do desenvolvimento do arcabouço teórico formado pelos conceitos de videoclipe pósMTV, mediação, gênero e gêneros musicais chegamos à conclusão de que os videoclipes no atual cenário cultural antes de serem produtos de divulgação de produtos musicais são mediações de performances públicas de gostos associadas aos gêneros musicais.

Palavras-chave: Videoclipe Pós-MTV. Gênero musical. Audiovisual.

\begin{abstract}
This article proposes a analysis the video clip Flei taking into account the articulations between genre, musical genre and online platforms for the provision of musical contents. It is believed that to understand that what is a video clip we must take into account the role that new audiovisual mediations play in an environment where the television grid no longer has the importance it had in the MTV era. Thus, we sought to analyze the music video for the song "Flei", by singer Daniel Peixoto, as a current example of how the signatures of gender and musical genre are articulated in political and aesthetic way. Thus, from the development of the theoretical framework formed by the concepts of post-MTV music video, mediation, genre and musical genres we conclude that video clips in the current cultural scene before being products for the dissemination of musical products are public performances mediations of tastes associated with musical genres.
\end{abstract}

Keywords: Post-MTV video clip. Music genre. Audiovisual.

\section{Prelúdio}

As diversas transformações que estão reconfigurando a música popular massiva nos últimos anos, seja em relação à produção ou aos modos de escutar música, parecem nos desafiar para que busquemos alternativas às nossas 
tradicionais categorias de análise. É em meio a esse cenário que este artigo propõe uma atualização da abordagem do videoclipe tal como apontado por Simone Pereira de Sá (2016) em suas configurações "pós-MTV", levando em conta que antes de configurar um formato unificado este produto faz parte de uma série de mediações musicais (Born, 2011) marcadas por uma diversidade de trânsitos estéticos, sonoros e sociais.

Assim, procuramos observar como o videoclipe Flei, do cantor cearense Daniel Peixoto, agencia música, performances de gênero e estruturas de interpelação (Butler, 2015) através do cruzamento de referências ao tecnobrega, observando a importância das mediações que envolvem questões de gênero (identidade) e gêneros musicais nos videoclipes, ou seja, das negociações genre ${ }^{1}$ $x$ gender $^{2}$ na música. Acoplamos a esta abordagem os apontamentos de Rincón (2016) que nos permitem adensar os olhares sobre Flei através das articulações sonoras e visuais que materializam lugares e identidades através da cultura pop, entendida aqui como uma experiência bastarda.

O bastardizado como marca do popular propõe que não há pureza comunicativa nem nas identidades outras (the other, o colonizado), nem nas tecnologias narrativas do mesmo (o colonizador hegemônico). O bastardizado nomeia o que habita o popular, esses jogos de sentidos impuros que combinam expressivamente 0 midiático com o arcaico, as estéticas do mainstream com os referentes de identidade (Rincón, 2016, p. 18).

Neste sentido, acreditamos que apesar de ainda ser vivenciado como um formato audiovisual de produtos musicais, o rótulo "videoclipe" pode ser mais bem compreendido por entradas múltiplas tal como parecem ser as inúmeras formas de circulação acopladas a esta experiência audiovisual. Em outras palavras, apresentamos um arcabouço teórico formado pelos conceitos de videoclipe pós- MTV, mediação, identidade de gênero e gênero musical que nos permite perceber o modo como os videoclipes atuais acionam escutas conexas, ou seja, um conjunto de heterogeneidades que integram música, audiovisual, entrevistas, participação em filmes e novelas dentre outros materiais, pressupondo tessituras de intrigas (narrações) que podem até ter o videoclipe (ou sua forma tradicionalmente conhecida) como elemento basilar, mas que não se esgotam nele. A opção pelo termo escuta não pressupõe uma hierarquia entre música e visualidade, mas a consideração de que a utilização do

1 Gêneros musicais.

2 Identidade de gênero. 
termo videoclipe para designar certos produtos audiovisuais mantém a música como relevo principal para este tipo de produção.

\section{Primeiro ato}

Desde a popularização da circulação digitalizada de imagens na internet o modelo de videoclipe centrado na grade televisiva, estilo MTV, foi colocado em cheque. Ao contrário da antiga divisão de programas por gêneros musicais ou por preferência da audiência (mais pedidos) assistir um videoclipe hoje significa adentrar um mar de indicações automáticas, comentários, likes e dislikes. Qualquer um que navegue pelas plataformas stream de produtos audiovisuais nota que ao invés de manter-se preso a uma grade musical fica-se atrelado a um sistema de recomendações quase infinito, que não deixa de ser outro modo de enredamento do fruidor. Estamos então diante de uma reconfiguração (a passagem da grade para o sistema de recomendação) que mantém resíduos de sua forma anterior (a sequência de videoclipes que aparentemente possuem alguma "similaridade").

Simultaneamente a este processo nota-se o aumento de oportunidades para criação de paródias, versões personalizadas e produções de baixo custo no mundo do audiovisual musical, ou seja, possibilidades de intervenções e reinvenções mais diretas por parte dos fruidores. A permanência da utilização do termo videoclipe para produções tão diversas mostra que uma experiência comum se solidificou nesta passagem por diferentes temporalidades, espaços e suportes. Assim, mesmo diante de tantas mudanças quando somos convidados a ver um videoclipe sabemos que estaremos diante de uma articulação entre música e imagem que são entrelaçadas por uma faixa musical com referências de pertencimento a algum gênero musical.

Longe de apontar para a solidificação de um formato, o que se observa é uma amplificação em direção a uma diversidade de modos de produção, circulação, consumo e apropriação do videoclipe. Isto nos faz refletir com Lawrence Grossberg que "[...] nós temos de parar de pensar sobre a mídia ou mundos mídia e interrogar mundos que são mediados por modos que nós ainda não conceitualizamos" (Grossberg, 2010, p. 221)3. Propomos então pensar o videoclipe como um dispositivo expressivo que articula uma série de mediações culturais a partir de uma trama audiovisual assentada em uma faixa musical como uma associação não hierarquizada entre imagens e música, ou

3 No original:" (I think) we will have to stop thinking about the media or about media worlds, and interrogate worlds that are mediated in ways that we have yet to conceptualize". Tradução dos autores. 
melhor, com posições de destaque em movimento, de picos de importância relativos e variáveis entre esses elementos sonoros e imagéticos.

Esta construção é pensada em diálogo direto com a proposta conceitual de "videoclipe Pós-MTV", desenvolvida por Simone Pereira de Sá.

Por videoclipe "Pós-MTV" me refiro a um conjunto heterogêneo de produções que circula preferencialmente na plataforma do Youtube, espraiando-se por outros ambientes; e que abrange um conjunto de fragmentos audiovisuais de origens heterogêneas que vão do vídeo do show postado por um fã, passando pela infinidade de paródias, tributos e homenagens e chegando até os vídeos "profissionais" que divulgam as novas músicas dos cantores com carreiras (mais ou menos) (Sá, 2016, p. 61).

Abordar o videoclipe como dispositivo expressivo nos permite observar um intricado processo de mediações que envolvem traduções, agenciamentos, valorações, performances de gênero e de gosto. É preciso esclarecer que o termo mediação, tal como o utilizamos, não pressupõe um mediador entre sonoridades e visualidades.

\begin{abstract}
Mediação, neste sentido, descreve uma casualidade não-linear; mapeia fluxos, interrupções e paradas que descrevem o devir ou autoprodução da realidade ou melhor, realidade-sempreconfigurada. Mediação é o movimento de eventos ou corpos de um conjunto de relações para outras como se elas estivessem constantemente transformando-se em alguma coisa diferente do que são. É o espaço entre o virtual e o atual, o devir atual (Grossberg, 2010, p. 191)
\end{abstract}

Mediações são processos de materialização de expressividades estéticas, sociais, políticas e econômicas dos videoclipes. Um importante articulador das mediações são as relações estabelecidas entre imagem e música a partir dos gêneros musicais. Os gêneros não são somente sonoridades, eles envolvem aspectos ideológicos, redes sociais, práticas comerciais e experiências que possuemcomocentronevrálgicoasexpressõesmusicais.Antes defuncionarcomo uma camisa de força ou uma etiqueta de gaveta, os gêneros musicais pressupõem conflitos e negociações que envolvem processos de comunicação dinâmicos.

4 No original: "Mediation, in this sense, describes a non-linear causality, it maps the flows, interruptions, and breaks that describe the becoming or self-production of reality or, better, reality-always-configured. Mediation is the movement of events or bodies from one set of relations to another as they are constantly becoming something other than what they are. It is the space between the virtual and the actual, of becoming actual". Tradução dos autores. 
As articulações entre gêneros musicais e videoclipes envolvem agenciamentos mercadológicos (direcionamentos e embalagens), textuais (estratégias de produção de sentido inscritas nos produtos musicais), estéticos (possibilidades de experiências atreladas às expressões audiovisuais da música), técnico-formais (produções, rotulações e endereçamentos de circulação) e sociais (interpelações, recepções, recomendações e apropriações). Não há fronteiras rígidas entre essas articulações, tratam-se de mediações.

Vamos destacar então duas importantes modulações das mediações dos videoclipes na cultura pop no mundo contemporâneo. A primeira é o importante papel exercido pelas articulações sociais em torno do videoclipe, e aqui contamos com o relevo dado por Itânia Gomes (2011) a esses aspectos, quando aborda os gêneros televisivos, inspirada pelo mapa das mediações, desenvolvido por Martin-Barbero.

A socialidade, mediação que articula matrizes culturais e competências de recepção, deixa ver os modos e usos coletivos de comunicação, as relações cotidianas que as pessoas estabelecem com os meios, gêneros e formatos midiáticos (Gomes, 2011, p. 119).

O videoclipe mantém características de sua configuração audiovisual englobando aspectos de sua televisualidade que é perpassada pelos gêneros musicais e por um emaranhado de "estratégias de comunicabilidade" que agrupam aspectos sonoros e visuais. Não se trata somente de imagens associadas a músicas, mas do modo como certos cenários construídos nas articulações entre gêneros musicais e imagens articulam visualidades musicais.

É possível falar dos cenários épicos do heavy metal, do sertão do baião, da Jamaica do reggae ou da metrópole do rap; [...] espaços associados a certas sonoridades, ou melhor dizendo, paisagens (com suas contradições, anseios e faltas) presentes na música popular massiva (Janotti Jr., 2006, p. 12).

É através da mediação dos gêneros musicais que os cenários possibilitam a materialização de assinaturas midiáticas de intérpretes e bandas. Mas isso não se dá somente a partir de um único videoclipe ou de uma faixa musical e sim, como dito anteriormente, a partir de narrações que envolvem audiovisual, processos de recomendação, agrupamento de produções, afirmações de gosto, letras, biografias, críticas culturais, entrevistas, etc. Desde já é preciso ressaltar que não reivindicamos qualquer verossimilhança entre as narrativas sonoroimagéticas e as vivências pessoais das cantoras, dos cantores e das bandas. Aqui tratamos do encenar-se, da construção de assinaturas ou dos feixes discursivos 
que compõem a construção de uma personagem. Devemos destacar também que quando acionamos o termo "personagem" não o consideramos no sentido de uma máscara que esconde um rosto e sim de uma assinatura que nos interpela e coloca em cena os atores da música popular massiva.

Assentados em Born (2011), acreditamos que as assinaturas midiáticas expressas nos videoclipes são importantes articuladoras dos quatro planos de mediações sociais que configuram a constelação de mediações do universo da música proposta pela autora, ou seja, 1) relações sociais em torno de performances, práticas coletivas e divisão de papéis inerentes ao mundo da música 2) vivências em torno de "comunidades imaginadas" agrupando seus participantes em públicos e coletividades baseadas em experiências musicais, 3) Agenciamento da música pelas formações etárias, étnicas, sociais e de gênero e 4) vínculos estabelecidos entre música e formas sociais amplas, geralmente implicadas nas bases dos sistemas de produção, reprodução e transformação da música envolvendo aspectos mercadológicos e sociais. Reforçando o percurso aqui proposto, destacamos que para Born os gêneros musicais são um importante operador destas mediações.

Em resumo, minha discussão de gênero como um ponto assumido de convergência ou tradução entre figuras estéticas, comunidades musicais imaginadas e uma ampla formação de identidade, destinase a desestabilizar o que é tantas vezes tomado como regularmente unido. Ao invés de qualquer vínculo assegurado entre música e amplas formações sociais, é analisando o gênero como uma sucessão de mediações mútuas entre duas entidades históricas autoorganizadoras - formações musicais (de um lado) e formações de identidades sociais (de outro lado) - que podemos compreender o modo como amplas formações de identidades sociais são refratadas na música e como gêneros musicais se entrelaçam a formações sociais em desenvolvimento (Born, 2011, p. 384).

Amplificando a indicação de que “(...) o videoclipe que circula no Youtube é um ator enredado numa rede afetiva e sócio-técnica distinta daquele do videoclipe da Era MTV" (Pereira de Sá, 2016, p. 62) pensamos a articulação dos gêneros musicais pelos videoclipes como "modulações afetivas", tais como enunciadas por Grossberg.

Afeto nomeia um complexo conjunto de mediações/efeitos que são, como sugere Thrift, a-significantes (embora possam produzir significação), não-individualizados (embora possam produzir individualidades), não-representacionais (embora possam produzir formas representacionais) e não consciente (embora possam produzir várias formas de consciência). Afeto refere-se à energia da 
mediação, uma questão (quantificável) de intensidade. Afeto age em múltiplos planos, através de múltiplos dispositivos, com efeitos variados (Grossberg, 2010, p. 193)

Em resumo, pode-se pensarqueritmos, texturas, tonalidades, sonoridades, cenários, personagens, encenações e apropriações configuram mediações que agenciam gênero musical e imagem no "vídeo Pós-MTV", em modulações afetivas que proporcionam modos de habitar e desabitar o mundo através da cultura pop.

\section{Solo}

Daniel Peixoto nasceu em Fortaleza, capital do Ceará. Em 2005, o cantor começou a ganhar popularidade com o duo de eletro-funk Montage, formado em parceria com o produtor musical Leco Jucá. Após apresentações em grandes eventos de música no país o duo alcançou repercussão no cenário nacional, participou de festivais no exterior e seguiu até meados de 2009. Com o fim do grupo Peixoto iniciou carreira solo, lançando o EP Shine ${ }^{6}$ em 2011 e o disco Mastigando Humanos ${ }^{7}$, em abril do mesmo ano. Em 2016, lançou o primeiro single de um novo trabalho chamado CRUSH - Manda Nudes feat. João Brasil.

O cantor cearense pode ser considerado um expoente da geração que se firmou no atual cenário da música brasileira, que conta com nomes como Johnny Hooker, Liniker e Pablo Vittar, artistas que articulam música a questões de identidade de gênero. Entendemos que as modulações afetivas da cultura pop sempre envolveram as articulações entre sexualidade, gênero e música, como por exemplo nas performances de Ney Matogrosso e Cássia Eller na MPB ou nas performances deartistas internacionais como Boy George, Madonna eElton John. O que parece diferenciar a geração de Daniel Peixoto é que o posicionamento de gênero é assumido como uma questão de posicionamentos articulados não só através de suas performances musicais bem como de entrevistas, dados biográficos e imagem pública. Isso nos faz pensar que as modulações afetivas presentes nas mediações dos gêneros musicais e das identidades de gênero (genre-gender) são centrais tanto para as construções de "masculinidades" na música quanto para suas desconstruções ou realinhamentos.

5 No original: Affect names a complex set of mediations /effects that are, as Thrift suggests, a signifying (although they can produce signification), non-individualized (although they can produce individualities), non-representational (although they can produce produce various forms of consciousness). Affect refers to the "energy" of mediation, a mater of (quatitifiable) intensity. Affect operates on multiple planes, through multiple apparatuses, with varied effects. Tradução dos autores.

6 Em formato digital e pela gravadora AbatJour Records.

7 Em formato digital e físico, pela gravadora Fora do Eixo. 
Em uma matéria publicada no estado do Ceará em $2011^{8}$ é possível notar a importância das articulações entre referências da música pop globalizada, gêneros musicais e os trânsitos entre o regional e suas rearticulações com os grandes centros de produção da cultura pop internacional. Na revista Daniel Peixoto é descrito como um "moderno retirante nordestino" enquanto sua trajetória musical é narrada através dos deslocamentos da cidade de Fortaleza para o Crato, São Paulo e posteriormente para a Europa. Também são destacados pela revista o fato de ter sido apontado como "o novo David Bowie" britânico The Guardian, e os elogios feitos pelo cantor Justin Timberlake à banda Montage, publicados no site pessoal do norte-americano. David Bowie, como se sabe, assumiu diferentes caracterizações ao longo de sua carreira, algumas de suas assinaturas musicais passavam pelo embaralhamento de normas de gênero (masculino x feminino). Esse dado pode servir de pista para algumas das formas de compreensão das performances de Peixoto a partir de suas referências musicais, sendo David Bowie uma delas. No tocante aos gêneros musicais, segundo a Cariri Revista, o "sertanejo cosmopolita" poderia ser agrupado no heterogêneo rótulo de "electro-brega-industrial-pop-punk-tropical".

Liga trip hop, menções às sonoridades dos 90's e vertentes do rock com sotaques nacionais no estrondo de pandeiros, atabaques, 'um tamborzão mais frenético', elementos do samba, macumba, carimbo, tecnologia e forró para refrescar o fundamento eletrônico (Bloc-Boris, 2011, p. 35).

Daniel Peixoto parece estar de acordo com as afirmativas, e declara-se também "muitíssimo influenciado pelos nomes novos, como IAMX, Placebo e Ladytron. "[...] Sou uma mistura, graças a Deus!" (Peixoto, 2011). Além das influências de Madonna e Bowie em sua carreira, ele relata a experiência de ter crescido vendo as apresentações de João do Crato, artista da cidade de Crato - no interior do Ceará, para onde Peixoto se mudou quando criança, o que nos permite pensar que antes de querer associar-se a uma trajetória pop desterritorializada trata-se na verdade de linhas de fuga diversas.

A minha referência de androginia também vem da música. Todos os meus ídolos trabalharam uma época de suas vidas nesse conceito da androginia: David Bowie, Madonna, Shirley Manson, Brian Molko,

8 Cariri Revista, com sede na cidade de Juazeiro do Norte, no Ceará, e que se dedica às histórias e culturas da região do Cariri cearense. Sua tiragem em 2016 foi de 10 mil cópias por edição.

9 Bowie, como se sabe, assumiu diferentes caracterizações ao longo de sua carreira, e algumas de suas assinaturas musicais passavam exatamente pelo embaralhamento de normas de gênero (masculino $\mathrm{x}$ feminino). 


\begin{abstract}
do Placebo, o lggy Pop, Marilyn Manson, todas as minhas referências musicais. O Ney Matogrosso! Todos eles tiveram esse momento da androginia, que nada mais é que essa ambiguidade do visual, das roupas ditas femininas e masculinas, e você misturar isso, e questionar essa coisa da identidade de gênero. Por que é que eu não posso usar um vestido? (Peixoto, 2015, [s. p.] $)^{10}$.
\end{abstract}

Observamos que os diversos gêneros musicais pelos quais transita Peixoto são mediações importantes na construção de diferentes corporalidades em performances musicais que aparentam ser construídas a partir de um choque produtivo entre lógicas de gêneros musicais e de "performances de gênero" (Butler, 2015).

O reconhecimento de Daniel Peixoto como "sertanejo cosmopolita" aciona imaginários que se contrapõem ao "macho sertanejo", ao "macho cosmopolita" do forró eletrônico e ao "mangueboy urbano", do manguebeat recifense, por exemplo. Também nos mostra que as entrevistas de Peixoto são relevantes por fornecerem diferentes facetas do cantor e por permitirem chaves de entendimento de suas ações performáticas, bem como pistas das conjunturas dos gêneros musicais que Peixoto aciona, reforçando a ideia de uma escuta conexa em ambientações que englobam canções, declarações, entrevistas, públicos, criticas, e videoclipes.

É essa a tessitura da intriga produzida por diferentes expressões que materializam a "assinatura midiática" de Peixoto através de relatos de si. Para Butler (2015)"relatos de si mesmo" são fornecidos a partir de ações interpelativas. Os relatos não nascem de si, ou pelo menos não somente de si mesmos, mas são acionados por um jogo de alteridades. Assim, a elaboração e fornecimento de um relato de si tornam-se possíveis a partir da interpelação ao outro e pelo outro.

Sermos desfeitos pelo outro é uma necessidade primária, uma angústia, sem dúvida, mas também uma oportunidade de sermos interpelados, reivindicados, vinculados ao que não somos, mas também de sermos movidos, impelidos a agir, interpelarmos a nós mesmos em outro lugar e, assim, abandonarmos o'eu' autossuficiente como um tipo de posse (Butler, 2015, p. 171).

Há diferentes formas de reconhecimento dos relatos, mas nunca de forma total ou projetada. Com isso, observando possíveis configurações de estruturas de interpelação nos videoclipes sustentamos que o espectador é parte fundamental na construção do "eu" discursivo acionado por Daniel Peixoto. $O$ observador se coloca como interlocutor, o "outro" do "eu" que se pretende. As

10 Em entrevista à TV Verdes Mares, afiliada da Rede Globo no Ceará. 
inscrições que os gêneros musicais embutem nestes produtos apontam para o outro, mas não um qualquer, e sim como um grupo de consumidores musicais que se materializa nas modulações afetivas dos "videoclipes Pós-MTV".

\section{Ária}

O videoclipe Flei foi lançado em janeiro de 2014, quase três anos após o início da carreira solo de Daniel Peixoto. Há um intervalo de quase três anos em relação ao lançamento do seu videoclipe mais conhecido, "Olhos Castanhos" (2011), que foi parte da trilha sonora da novela "Lado a Lado", da Rede Globo. Em comparativo de views, Flei, que não foi tema de novela, apresenta uma diminuição de acessos de quase $50 \%$ em relação a Olhos Castanhos, ainda que estes dados não possam ser resumidos à divulgação ou não divulgação pela telenovela (Olhos Castanhos, 2011 - 89,413 views; Flei, 2014 - 46,400 views).

Gravado em Fortaleza o videoclipe Flei apresenta uma canção que flerta de maneira direta com o tecnobrega, gênero popular de música eletrônica criado em Belém do Pará, que tem como uma de suas estrelas-divas Gabi Amarantos, uma cantora oriunda da periferia, fora de padrões de beleza hegemônicos e que se firmou por firmar-se em um entrecruzamento entre "vozes periféricas" e "sonoridades pop" da música eletrônica de pista. A canção de Daniel Peixoto materializa as rotas periféricas da música brasileira já em sua primeira estrofe no videoclipe, enunciando as pontes entre Fortaleza-Belém, em um jogo de vozes onde o cantor anuncia "a nova moda que vem do Ceará", enquanto a voz de Carol Texeira, que faz parceria com Peixoto na música, ao fundo, é sobreposta na mixagem e enuncia: "vem do Pará".

Estas mediações ficam evidentes nos cenários escolhidos para a encenação de Daniel Peixoto. Antes de ser uma Fortaleza singular, dos cartões postais e das praias, o videoclipe apresenta a rua e o mercado popular. Após a projeção do nome de Daniel Peixoto e da introdução da batida eletrônica, as imagens se apresentam em corte seco, freneticamente. São imagens de bonés, celulares, calcinhas, shortinhos, "bundas", barrigas e alimentos como churrasquinho, batata frita e caldo de cana.

É interessante notar que não se trata de fazer emergir Fortaleza como um novo porto nas rotas das sonoridades periféricas brasileiras. Desde os anos 1990, após o sucesso nacional da banda de forró Mastruz com Leite, a capital do Ceará é conhecida como uma das bases descentradas da música brasileira produzida fora dos eixos tradicionais da indústria da música no país. Na verdade, podemos 
ver uma reiteração das rotas corsárias que vão de Belém a Fortaleza, passando pelas articulações de outras personagens evocadas na letra ${ }^{11}$.

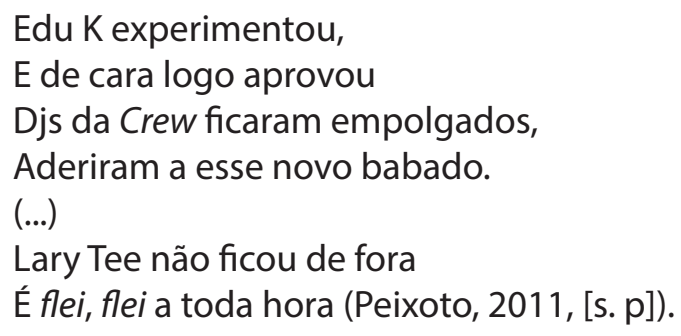

Pode-se notar diversas mediações espaciais atravessando, em camadas, o videoclipe, pois se há referências diretas a Belém e Fortaleza, percebe-se também, referências cifradas a São Paulo, Seattle e aos trânsitos possibilitados pelas reterritorializações da música eletrônica.

Daniel Peixoto canta como é prazerosa a prática do sexo oral-anal através da descrição de como ele deve acontecer. Flei, título da música, é uma adaptação utilizada por Peixoto para a expressão fleur-de-rose, ou "beijo-grego", como se chama popularmente o sexo oral-anal no Brasil. No videoclipe, há uma cena em que o cantor senta em uma cadeira ao ar livre, levanta as pernas e fica em posição que sugere a prática do Flei. Não é preciso compreender estas cifras para adentrar nos chamados corporais do vídeo, mas ela é uma pista para encenações que envolvem tanto um público específico, bem como para a abertura para outras alianças afetivas.

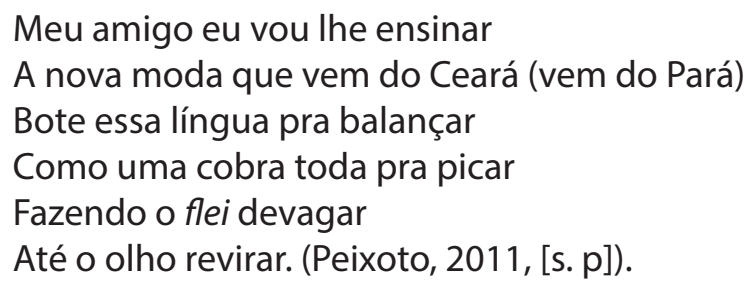

Pode parecer ainda que se trata de uma apropriação direta de algumas estratégias popularizadas por diversos gêneros da música popular periférica, como a referenciação a outros músicos; o uso do bordão "Sucesso!"; a autonomeação ("Daniel Peixoto, o popstar do melody"); uma letra de rima fácil cantada em reiterações rítmicas sobre uma base eletrônica e a memorização fácil

11 Edu K é um músico e produtor gaúcho que foi projetado nos 1990 com o sucesso de sua banda, Defalla. Apesar de associado ao rock sempre se rotulou como "eclético", afirmando sua aproximação com música popular periférica com o lançamento do disco do The Brega. Djs da Crew é uma citação da festa de música eletrônica paulista Crew. Larry Tee é um famoso produtor/dj de Seattle, EUA, creditado como o inventor do gênero eletrônico electroclash, reconhecido por incorporar batidas do rock à música eletrônica. 
do refrão, repetido várias vezes. Mas tanto o acabamento audiovisual, quanto a citação de personagens que transitam entre festas cults e gêneros musicais distintivos, dão a impressão de que antes de ser somente uma celebração do tecnobrega, a canção celebra um público que partilha as cifras do universo gay.

De outro lado, não se deve deixar de notar que DJ Chernobyl, produtor da faixa, é o nome de pista do guitarrista e produtor gaúcho Fredi Endres, que ficou conhecido por tocar na banda Comunidade Nin-Jitsu, conhecida por colagens musicais entre rock efunk. Isso mostraqueas mediações musicais têm comotraços marcantes a emulação do tecnobrega através de acabamentos mais refinados.

No videoclipe, Daniel Peixoto e seu filho ${ }^{12}$ são apresentados após o corte de cabelo no salão da Roberta, todo decorado em rosa. As imagens de Daniel Peixoto junto ao seu filho no videoclipe de uma canção homoafetiva são atravessadas por diversas mediações que parecem não coadunar com o mundo encarcerado da heteronormatividade, inclusive na valorização do sexo a partir do ânus, e não da dicotomia pênis/ vagina. As modulações afetivas do vídeo envolvem desde marcas da paternidade entre homo e bissexuais, até a carnavalização pop-popular como antídoto contra o binômio bom-mau gosto. Os cortes que articulam visualidades e sonoridades no vídeo assumem o "Brasil pop-popular"como uma feira que dança, partilhando um movimento, ao mesmo tempo, conjunto, conflitivo e não-consensual. A ideia de "Brasil pop-popular" é alinhavada no videoclipe pela reiteração do amarelo e do verde, sobressaltados pelos efeitos gráficos e pelo conhecido bordão "Brasil!", usado inicialmente nos jogos da seleção brasileira de futebol.

Há um jogo entre modulações afetivas em torno dos prazeres do sexo, da circulação de música, vídeos pornográficos, CDs de videogames e sua acessibilidade, materializados na disponibilização destes produtos no mercado popular. A própria edição do videoclipe, apesar do bom acabamento e dos traços limpos, emula em alguns momentos as produções sem muitos recursos, que marcam parte das produções caseiras que circulam na internet.

12 O filho de Peixoto pode ser reconhecido no vídeo graças às suas aparições nas redes sociais do cantor, em fotos ao lado do pai. 
Figura 1 - DVDs pornográficos, shows e games são comercializados ilegalmente.

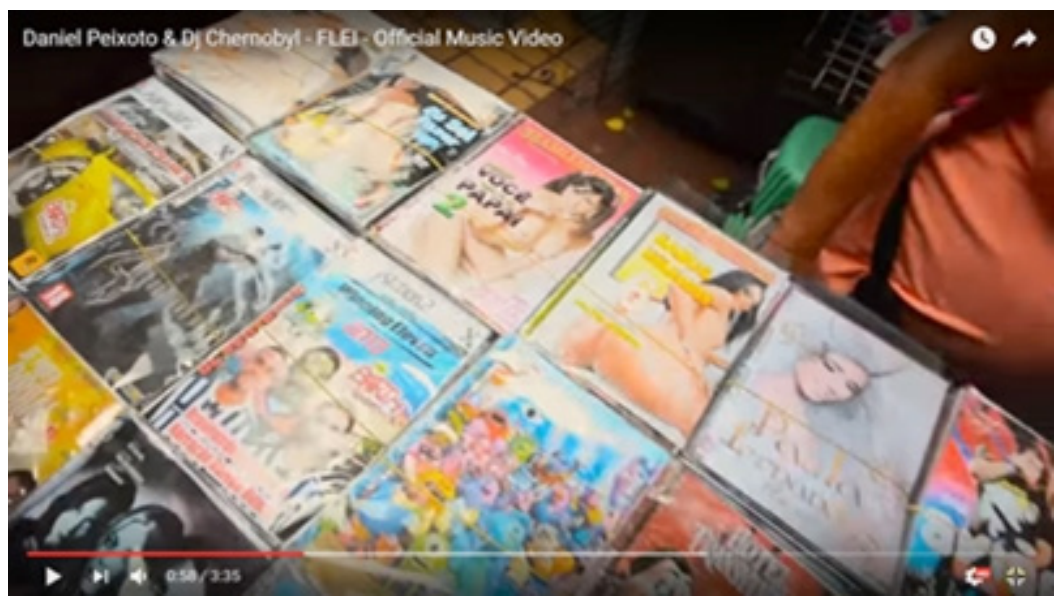

Fonte: Frame do videoclipe Flei, no YouTube.

A estratégia da inscrição das marcas de produção do próprio vídeo conectasea produções do tecnobrega, como o videoclipe "Xirley" (2012), canção do músico pernambucano Zé Cafofinho interpretada por Gaby Amarantos. Apesar de ser filmado em estúdio, o vídeo da cantora paraense traz cenas de feiras com bancas de CDs, do processo de produção caseira de música e da ascensão ao estrelato de Xirley Xarque, uma espécie de alter-ego da cantora.

\footnotetext{
O clipe permite uma leitura maior e mais ampla do que a sua história aparenta transmitir. O tecnobrega está ali muito bem representado sob um filtro pop de seu universo musical: a batida eletrônica marcante aliada a instrumentos e letras românticas, a produção caseira de CDs e DVDs, a divulgação informal através de camelôs e comércio informal, o trabalho insistente feito pelo próprio artista e, por fim, o resultado dos anos na batalha (Dias, 2012, p. 1).
}

Este tipo de palimpsesto é uma estratégia que se firmou não só como citação, mas como materialização de um circuito de produção musical que possui diversas camadas de mediações reiterativas. Tanto em Flei (2011) quanto em "Xirley" (2012), os videoclipes têm como uma de suas modulações afetivas a alusão a parte do universo de distribuição da música tecnobrega articuladas através das feiras públicas, marcadas pelos excessos de cores, mercadorias e pessoas, aspectos refratados no videoclipe pela circulação de Peixoto pelos corredores, pela colorização digital quente de parte dos cenários e pelo jogo de edição entre a materialização do cantor, mediador da apresentação de comerciantes, carregadores, consumidores, dançarinos e espectadores .

A presença de CDs e DVDs não-oficiais, espelhados pelas bancas dos camelôs no videoclipe aciona estratégias de circulação e apropriação próprias à música e à circulação do "videoclipe Pós-MTV"(Sá, 2016). A enunciação de Daniel 
Peixoto como "popstar do melody" no videoclipe é outro processo de mediação que o articula aos gêneros pop-populares. Vale lembrar que a enunciação do nome de quem canta foi uma estratégia mercadológica criada na época da popularização da venda dos CDs piratas compilados por gênero musical, o que permitia aos ouvintes saber de quem era aquela música específica que ele ou ela estavam ouvindo. De traços de marca produtiva, a assinatura enunciada de Peixoto em Flei passa a ser uma referência afetiva à música popular periférica.

Estas marcas também são reiteradas por várias imagens em que vemos as bancas de CDs não oficiais e quando Daniel Peixoto canta o refrão, tendo como cenário uma barraquinha de venda de aparelhos de som e televisão. Outra mediação é efetuada pelas roupas brancas do cantor e por sua branquitude, que servem para como contraponto à estampa "África" em sua camiseta e o destaca em meio à profusão de peles que transitam nos becos do mercado. Além das sonoridades que demarcam o gênero tecnobrega dos sintetizadores no videoclipe, há mulheres que parecem executar de forma conjunta uma coreografia tecnobrega para o Flei.

\section{Figura 2 - Mulheres dançam coreografias similares às do tecnobrega.}

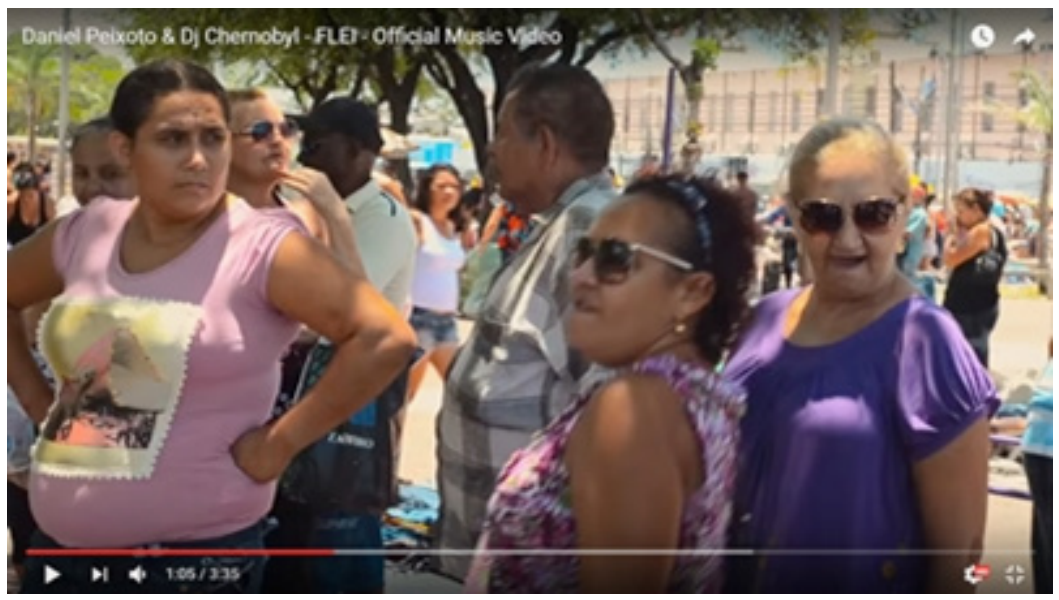

Fonte: Frame do videoclipe Flei, no YouTube

Outra sequência que ganha destaque é a encenação da street dance com imagens em que Daniel Peixoto interage com o grupo The Titans ${ }^{13}$. Os grupos de street dance são comuns nos imaginários do rap. A referência nos faz atentar para as influências também notáveis de MCs e rappers na construção dos estilos de cantores brasileiros no funk carioca, no pagode baiano e no tecnobrega. No videoclipe os garotos dançam em uma quadra de futsal, entrecortada por

13 Conforme creditado na descrição do videoclipe, disponível para visualização na rede social YouTube. 
imagens de um jogo de futebol. Se em um primeiro momento pode parecer que este seria um lugar de afirmação heteronormativa, o videoclipe parece tentar desconstruir essa imagem através de alianças afetivas entre Peixoto, que parece integrado ao grupo quando dança com os meninos. Há também a imagem de uma mulher de chinelos e calça colante dançando sensualmente junto com o grupo em cortes que se demoram sobre barrigas, cinturas e calções dos dançarinos, que estão sem camisa (Figuras 34 e 35). As delimitações do que socialmente é compreendido como espaços de ocupação, danças, práticas ou estilos gays e/ ou heterossexuais são borradas no vídeo, deslocando-se dos lugares comuns de gênero, masculinidades e feminilidades e das sexualidades heterossexuais e homossexuais.

Figura 3 - Peixoto se junta ao grupo de dança de rua.

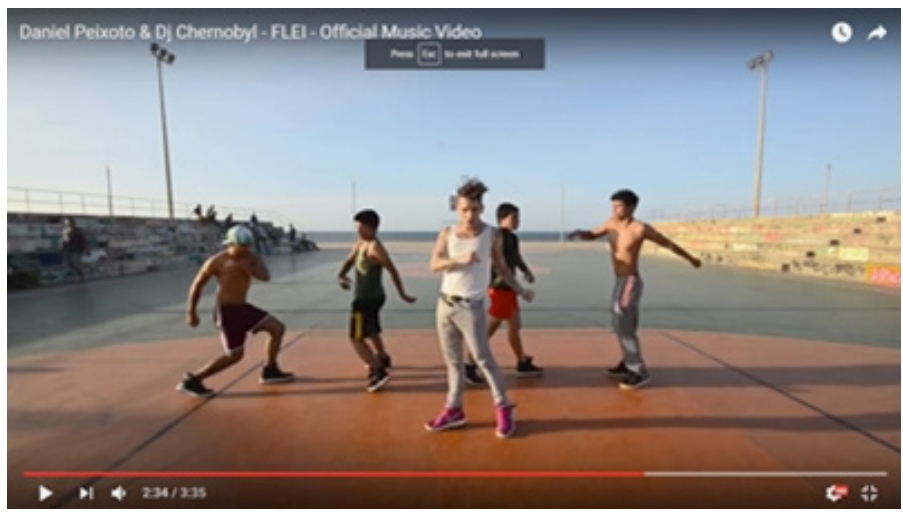

Fonte: Frame do videoclipe Flei, no YouTube.

Figura 4 - Danças e esportes se misturam no mesmo espaço.

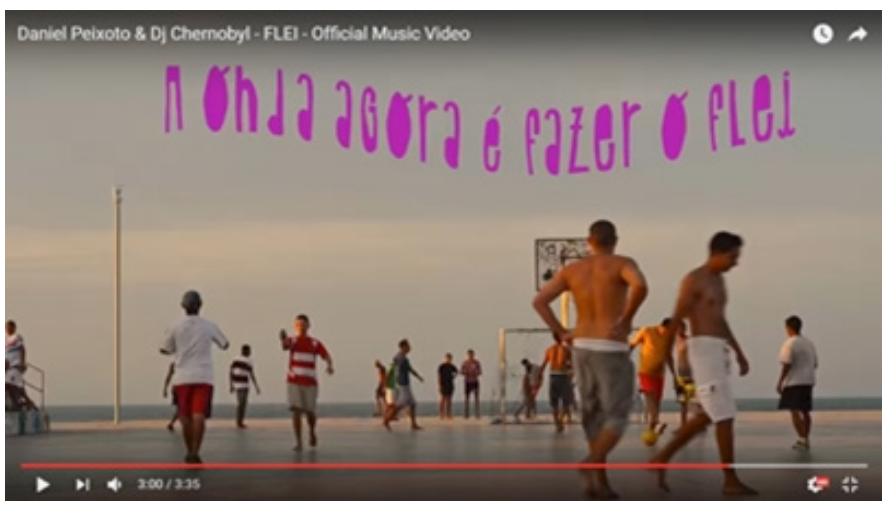

Fonte: Frame do videoclipe Flei, no YouTube.

Além das imagens sensuais e do tom erótico anunciado na letra da canção, podemos visualizar a influência de efeitos especiais em frases que se sobrepõem às cenas, com trechos da música e na coloração de diversos objetos (Figura 36). A edição das imagens também remete à pop art. $\mathrm{O}$ ato do "Flei" 
é materializado em uma cena que Daniel Peixoto passa a língua na lente da câmera pintando-a de roxo. Aqui, os aspectos eróticos de "Flei" ganham relevo através da intensidade visual do efeito utilizado na edição.

Figura 5 - A língua colorida de Hooker remonta a tendências da pop art enquanto simula um "beijo grego".

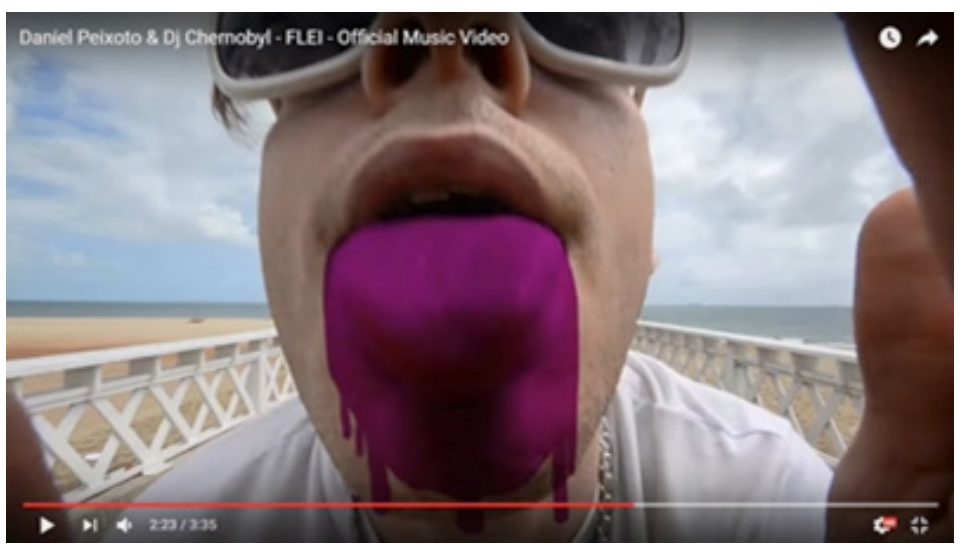

Fonte: Frame do videoclipe Flei, no YouTube.

\section{Apogeu}

É tentador finalizar dizendo que a carnavalização é o que funda partilha do comum entre as diversas mediações e modulações afetivas presentes em Flei. Mas se assim o fizéssemos estaríamos cedendo às facilidades de um binarismo que tanto pode servir para um populismo fácil ou somente para a valorização do cult como distinção em meio à cultura pop. Este caminho não nos permitiria enxergar as diferentes modulações que envolvem o cantor - jovem, homoafetivo, branco, de classe média - os dançarinos de rap e os transeuntes do mercado.

Masoquesepostulaaquiérepensaro próprio populareosatravessamentos do "videoclipe pós-MTV" através do modo como Flei amplifica, como propõe Omar Rincón, as próprias fricções que caracterizam o "pop-popular":

O popular bastardizado é um quilombo ou um sancocho de tudo: autenticidade, resistências, submissões, cumplicidades, inovações e aberrações. Tudo junto como nos pratos da comida típica latinoamericana, Tudo junto, revolto e saboroso: simultaneidade de catarse, subjugação e resistências e reinvenções. A bastardização popular é, então, isso que joga entre a cultura mainstream que se nutre do inglês, do made in USA e a hierarquia cool (Martel, 2011), mas também bebe e goza com os corpos, as músicas e as telenovelas (Rincón, 2016, p. 38). 
Se há momentos de linhas as articulações entre personagens diversos quando Peixoto sai dançando pelos corredores do mercado com uma menina vestindo a camisa do Fortaleza Esporte Clube, no aperto de mão de passagem com um trabalhador ou na reunião entre o grupo de street dance e a mulher que aparece para dançar com eles e Peixoto, também há momentos em o videoclipe traz desencontros realçados pela edição em corte seco que fazem emergir outros modos de encenar o pop-popular. Desde as primeiras imagens vemos olhares ensimesmados para a câmera. Um senhor observa enviesado, sentado de lado em sua cadeira. Há no início do vídeo uma fiscal que parece tentar organizar a aleatoriedade dos ambulantes. Nota-se também a indiferença das mulheres sentadas na barraca de eletrônicos enquanto a música é performada por Peixoto. No videoclipe vemos camelôs que não parecem confortáveis com a proximidade do cantor, a indiferença de um senhor que debulha feijão, o olhar irônico do cantor por cima do ombro de um ambulante, certa indecisão de vendedores entre participar e observar de modo distanciado enquanto Daniel Peixoto experimenta os óculos da banca de vendas diante de um espelho.

Materializados propositalmente no videoclipe estes deslocamentos desvelam tensões, desentendimentos que antes de situarem a personagem de Daniel Peixoto, e Flei, em um idílico pop-popular de alianças sociais de grupos minoritários mostra que os atravessamentos entre o cult-popular da música eletrônica e brega pop da música popular periférica nos colocam outras questões para se pensar a constituição do popular.

Não se trata de"tenhamos meios de conteúdo politicamente corretos": sem racismo, sem machismo, sem homofobia, sem classicismo. Não. Porém, assumir o racismo, o machismo, a homofobia, o classicismo faz parte da conflitividade da sociedade, do relato e do agonismo político; assumir que são mais do que assuntos, são também, formatos estéticas e narrativas. Assim como na cidade se trata de não negar o conflito, mas sim de o processar de maneira agonística, o relato midiático tem como constitutivo o conflito (e não somente conteúdos). A diferença política está em como e por quais vias se resolve o conflito. $\mathrm{E}$ os modos de resolver o conflito se concretizam no modo do relato (Rincón, 2016, p. 41).

Como esperamos ter demonstrado ao longo do artigo o agenciamento audiovisual do videoclipe Flei (2011) aciona mediações que propõem inúmeras possibilidades de trânsitos na cultura pop-popular contemporânea. Ao misturar tecnobrega e electroclash, brega e pop arte na balbúrdia dos mercados e das praças públicas, os trânsitos da música de Daniel Peixoto parecem mostrar que no atual caldeirão cultural os afetos não tratam somente da partilha, mas também de encontros e desencontros. Como aponta Rancière, ao discorrer 
sobre o sensível na política: "Trata-se de uma distribuição possível, que é também uma distribuição da capacidade que uns e outros têm de participar nessa mesma distribuição do possível" (2011, p. 19). Deste modo, as mediações de Flei articulam modulações afetivas em torno de encontros necessários materializados no "videoclipe pós-MTV", mas não necessariamente pacíficos.

\section{REFERÊNCIAS}

BORN, Georgina. Musica and Materialization of Identities. Journal of Material Culture, Sage, v. 16, n. 4, p. 376 - 388, 2011. https://doi.org/10.1177/1359183511424196.

BUTLER, Judith. Relatar a si mesmo. Crítica da violência ética. Belo Horizonte: Autêntica Editora, 2015.

BLOC-BORIS, Kiko. Daniel Peixoto tem fome de viver. Cariri Revista, Juazeiro do Norte, v. 1, n. 3, p. 30-38, out. 2011.

DIAS, Eduardo. "Eu vou samplear, eu vou te roubar": cena, mercado e música do tecnobrega no videoclipe Xirley. In: XXXV Congresso Brasileiro de Ciências da Comunicação, Intercom, 35, 2012, Fortaleza. Anais... Fortaleza: UNIFOR, 2012.

GOMES, Itânia. Gênero televisivo como categoria cultural: um lugar no centro do mapa das mediações de Jesús Martín-Barbero. Revista Famecos, Porto Alegre, v. 18, n. 1, p. 111-130, jan./abr. 2011.

GROSSBERG, Laurence. Cultural Studies in The Future Tense. Durham/London: Duke University Press, 2010.

JANOTTI JR., Jeder. Por uma análise midiática da música popular massiva. Revista E-Compós, Brasília, v. 6, n. 2, p. 1-15, maio./ago. 2006.

RANCIÈRE, Jaques. O Que Significa "Estética"? Trad. de R. P. Cabral. Projecto Imago, 2011. Disponível em: http://cargocollective.com/ymago/Ranciere-Txt-2. Acesso em: 16 mai. 2017.

RINCÓN, Omar. O Popular na Comunicação: Culturas Bastardas + Cidadanias Celebrities. Revista Eco-Pós, Rio de Janeiro, v. 19, n. 3, p. 27-49, 2016. http://dx.doi.org/10.29146/eco-pos.v19i3.5420.

SÁ, Simone Pereira de. Somos Todos Fãs e Haters? Cultura Pop, Afetos e Pertormance de Gosto nos Sites das Redes Sociais. Revista Eco-Pós, Rio de Janeiro, v. 19, n. 3, p. 50-67, 2016. http://dx.doi.org/10.29146/eco-pos.v19i3.5421. 


\section{GALDINO, Erik. Confira fotos de Daniel Peixoto, ex-montage, em ensaio Queer.} Disponível em: https://disponivel.uol.com.br/acapa/revista/confira-fotos-dedaniel-peixoto-exmontage-em-ensaio-queer/13/38/9256. Acesso em: 27 out. 2017.

GLOBO TV. Daniel Peixoto fala sobre a volta do Montage. SE LIGA VM. 11 abr. 2015. Disponível em: http://globotv.globo.com/tv-verdes-mares/se-liga-vm/v/seliga-vm-daniel-peixoto-fala-sobre-a-volta-do-montage/4102629/. Acesso em: 13 mai. 2017.

PEIXOTO, Daniel. FLEI. YouTube. 28 jan. 2014. Disponível em: https://www.youtube. com/watch?v=mc2ul82hnJ0. Acesso em: 13 mai. 2017.

Recebido em: 6/6/2017

Aprovado em: 26/9/2017

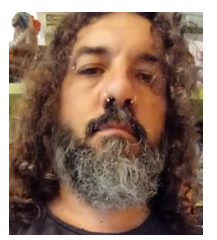

Dados dos autores:

Jeder Janotti Junior | ederjr@gmail.com

Universidade Federal de Pernambuco (UFPE)

Professor do Programa de Pós-Graduação da Universidade Federal de Pernambuco (UFPE)

Endereço do autor:

Av. Prof. Moraes Rego, s/n Cidade Universitária

50670-901 Recife - Pernambuco - Brasil

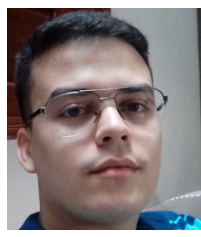

João André Alcantara | joaoandrealcantara@gmail.com

Universidade Federal de Pernambuco (UFPE)

Doutorando do Programa de Pós-Graduação em Comunicação da Universidade Federal de Pernambuco (UFPE)

Endereço do autor:

Av. Prof. Moraes Rego, s/n Cidade Universitária

50670-901 Recife - Pernambuco - Brasil 